\title{
Body scape: A wearable inquiry into body-landscape relations
}

\author{
Alice Lewis
}

\begin{abstract}
This essay arose from my current doctoral research investigating the relative position of the human body and its garment cladding within the urban landscape as a generator of place, space and spatial change. I critique the view that our bodies are separate from the landscape, building on the phenomenological foundations of Martin Heidegger and Otto Bollnow, among others. Through this lens, we are able to understand the reliance of the human body upon the earth's surface for existence, though there is a marked division between the 'body' and the 'landscape' inherent in phenomenological theory that places us as separate from the space. Employing a combination of theoretical and project-based discussion, I attempt to reveal the inexistence of this separation and, as such, to understand the body as a dynamic material substance of the world. If we consider this in light of the rapidly increasing global urban population then this 'body material' becomes one of abundance and significant spatial phenomenon.
\end{abstract}

This position is articulated through a wearable project that I conducted for the 2011 Meeting of European Design Students at the University of Ljubljana, Slovenia. The project, titled 'A Conversation of Space', investigated and provoked the dialogue of space occurring between our bodies and the surrounding landscape. Through the considered design and construction of abstract garments that distorted and disrupted the occupation and the perceived identity of particular spaces, the project attempted, through public 'performances', to reveal and understand the material ramification of our body presence in the world. The purpose of the inquiry was not to create a new reality or identity within the landscape but, rather, to draw attention to the significance of our bodies in creating the spaces that we know to exist.

This inquiry arose out of a desire to explore and understand the material implications of our physical bodies within the contemporary urban landscape. So often when employing the term 'landscape', we position ourselves as separate from the subject, as onlookers or passive viewers of a place. But, is it the case that we are, in some way, apart from the spaces that we inhabit? The Conversation of Space project, on which this essay focuses, argues that we are not 'a-part-from' the landscape but, rather, 'a-part-of' it. This argument is largely derived from the idea that the landscape is, in fact, infinite. As such, our physical bodies are inescapably positioned within this infinite landscape, meaning that our bodies must hold some material presence in the world and, hence, are a constituent component of that landscape. Our physical form places us as generators of both space and spatial change. This position was investigated at a workshop that I conducted for the Meeting of European Design 
Students at the University of Ljubljana, Slovenia, in the summer of 2011. I called the workshop 'A Conversation of Space' as its purpose was to investigate and provoke the dialogue that occurs between our bodies and the surrounding landscape in order to understand the material ramification of our body presence in the world. Over a two-week period, the participating students and I developed a series of garments as our research tools. The garments were designed to exaggerate particular material properties of the human body within the urban landscape. When the students wore the garments, the garments distorted and disrupted the occupation and perceived identity of a particular space. We were, in effect, researching the implications of the body through the material of the body itself. The purpose of the inquiry was not to create a new reality or identity within the landscape but, rather, to draw attention to the significance of our bodies in creating those spaces that we know to exist.

The inquiry into body-landscape relations that underpins this project arose some years ago during my postgraduate study in landscape architecture at RMIT University in Melbourne. It was, for a large part, born out of a fascination with the sheer mass of bodies that negotiate the streets of the city. As I watched the choreographed movements of those urban traversers, advancing across streets at the signal of their traffic light conductor, weaving with accuracy, sidestepping and changing speeds to make way for each other, it was overwhelmingly obvious to me that all these people, these daily dancers of the city streets, were significantly, yet somewhat unconsciously, altering the space for the people around them. While this observation may not have been as revolutionary as I thought it at the time, it went on to become a recurring theme in my teaching and doctorate in the same field. As a landscape architect, I am familiar with the design and allocation of space 'for' people but, in the city street, I was fascinated by how the people 'made' the space around them. I observed a spatial potency in the human form and bodily motion that was missing from the current discourse in landscape architecture. Each body resonated with the bodies nearby, causing a collective negotiation of the landscape, an ongoing dialogue of body-landscape relations. Does this not, then, place the body as a material component of the landscape itself? And, better still, could we employ that body material to create particular spatial scenarios?

\section{Language and landscape}

I have speculated on numerous occasions throughout my research that the absence of the human body from the material inventory of the landscape architecture discipline was due, in part at least, to the linguistic use of the term 'landscape'. When referring to places and landscapes of all typologies there is an overriding tendency towards an objective vocabulary (Appleton 1996) that positions us outside of that of which we speak. In verbally placing ourselves as solely the viewer of these spaces, we accept and endorse our separation from 
both the description and the space. We are positioning ourselves as 'a-partfrom' the landscape rather than 'a-part-of' it, making the material categorisation of ourselves as being 'of' the landscape problematic. After all, how can we be a material component of something we are not part of? The issue with this objective use of the term is that 'landscape', as it exists in reality, is boundless and infinite. Contemporary landscape architect James Corner illustrates this beautifully, stating that:

unlike paintings or novels, there is little opportunity to wander or turn away from the experience of landscape. Spatially, it is all-enveloping and surrounds us, flooded with light and atmosphere. Irreducible, the landscape controls our existence extensively; it permeates our memories and consciousness, and enframes our daily lives.

Not only does landscape surround us, but it does so in a limitless way. (1992: 146)

Corner's all-enveloping scenario suggests that, while we may have the ability to see the landscape objectively, we are always and inevitably immersed in it. The Conversation of Space project adopts Corner's position as a foundation on which to understand our embodied existence in space. It follows that, if the ground on which we stand is part of the infinite landscape, then our bodies must be inescapably positioned within it.

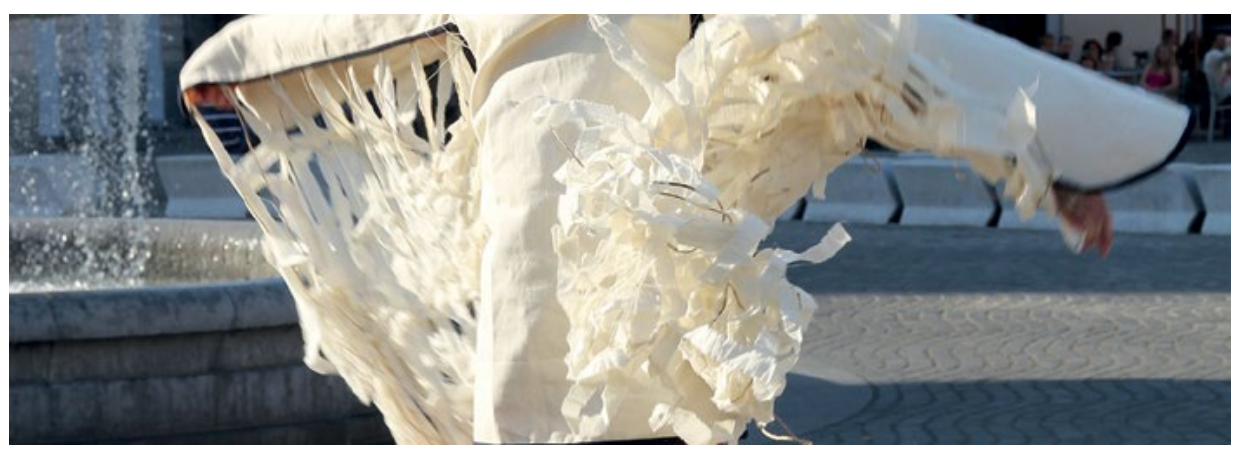

Figure 1. Elastic Space performance-in progress, 2011, calico, webbing, string, thread

Photo: Alice Lewis

\section{Body, ground, materiality}

There is an unquestionable truth that, as humans, we rely on the earth's surface for our existence; our relationship with the ground is what allows us to move, as we do, through space. Immersion of the human form in the world, on its surface and experiencing space with the body is a dominant aspect of phenomenological theory (Norberg-Schultz 1976). The inevitable circumstance 
of 'being' and existing in the world and on its surface has been developed and discussed at length by Martin Heidegger (1971), perhaps the most prominent figure in phenomenological theory to date. In his 'fourfold' division of the world (earth and sky, man and divinity), Heidegger speaks extensively on the position of 'man' dwelling in the world, between the earth and the sky. This space between the earth and sky is what we might call the 'landscape' and, hence, we can position our bodies as receptive beings on and in the landscape surface on which we dwell. Another phenomenologist, Otto Bollnow, revisited this idea some years later, stating that it is this surface between the earth and the sky that provides the foundation on which we must carry out our existence-we are unable to rise above it for any length of time, nor (while still living) to integrate ourselves into its soils. It is to the border between the two spaces of sky and ground that 'man [sic] is bound with his life' (1963: 47). What is apparent in the phenomenological positioning of the body in the world and on its surface is the ever-present distinction between the 'body' and those more commonly accepted landscape spaces of ground and sky. There persists, however, a reality that we must physically occupy the earth's surface. That we are positioned on, if not in, this infinite landscape surface.

The material distinction between 'body' and 'landscape' has been a recurring encounter throughout my research to date. To begin, while phenomenology entails a return to things, or an understanding of those objects that also occupy the earth's surface through an embodied encounter, the point is made clear that 'man [sic] is not a thing' (Heidegger 1971: 21). That we can experience with our bodies those things that make up the landscape does not give us licence to be included in the landscape. There is a rift in phenomenological theory that divides the body from those things it experiences on the earth's surface. Recently, the anthropologist Tim Ingold devoted a chapter of his book Being Alive (2011) to the difficulties of categorising the material components of the world, inclusive of human bodies. Ingold lists scores of approaches to the matter of classification that have been proposed by theorists from an array of disciplines though, throughout the chapter, there emerges an undeniable tendency to position the human body (our own as well as others) as distinctly separate from the landscape. We are positioned, once again, between the solid and gaseous substances of Heidegger's 'earth' and 'sky'. Take, for example, the system laid down by psychologist James J. Gibson that includes the three categories of medium (air), substance (ground) and surface (the convergence point of air and ground) (1979). This system of categorisation explains the distinction between earth and sky, but where do the materials of plants and animals fit? Surely they are part of the material world? In response, Ingold raises the question that '[i]f, moreover [plants and animals] are part of the material world, then the same must be true of my own body. So where does this fit in? If I and my body are one and the same, and if my body indeed partakes in the material world, then how can the body-that-I-am engage with that world?' (2011: 22). That we exist within the landscape is a more manageable concept than that we could, in fact, 
be part of the landscape and hence part of its material existence. But, we do exist within the landscape and, therefore, must hold some material and spatial presence. We must, in some way, encounter 'bodies' as we encounter 'things' in the phenomenological sense.

So, regardless of our categorisation system, there is an emerging logic that our material presence in the landscape must be both a generator of space and spatial change insofar as our bodies alter the operation and perception of the landscape in which they exist. Consider this scenario: if we encounter someone (another body) sharing the same direct line of movement as ourselves, yet advancing directly towards us, we may find the need to manoeuvre ourselves around the physical form of the other body in order to continue on our journey. The same would be true of the other party. In the event of neither party altering their line of traversal, we would soon be in an awkward situation; standing still, chest to chest, nose to nose, the physical form of our body preventing the forward advance of either party. Interestingly enough, this is a scenario that rarely happens (Whyte 1988). Instead, we select paths of least resistance, as I observed while walking, fascinated, through crowded urban streetssidestepping and changing speed to decrease the probability of ending up in that potentially awkward spatial engagement. Otto Bollnow offers an explanation of this situation, saying 'that [the body] is spatial does not therefore mean that the human being occupies a certain space with his body ... It means that the human being is always and necessarily conditioned in his life by his behaviour in relation to a surrounding space' (1963: 23). If this position is considered in relation to the traversal of an urban street, then our position within the landscape is determined in equal parts by the built configuration of the space that we are in as well as those other material bodies that simultaneously traverse the landscape. So, the body that we encounter, and either stand against or alter our path to avoid, is, to the extent that it is a tangible material form, as much a-partof the landscape as Gibson's 'substances' and which have similar effect on our movement. Regardless of our classification, we cannot deny that our material presence in the landscape is one of spatial significance.

\section{A Conversation of Space}

The Conversation of Space project was developed to explore the spatial significance of our human bodies in the urban landscape. The workshop was based on the idea that, if we have a physical form, then we must also hold material properties that create new spatial conditions in the part of the landscape that our bodies inhabit. The project uses a combination of specifically designed garments and wearers to directly investigate those perceived 'material' implications of having a body in the landscape. The garments, conceptualised and made over the two-week duration of the workshop, were worn in public 'performances' in order to test their implications in a practical sense. The performances were 
unconventional and constituted a publicly observed wearing of the garments by the participating students in the urban landscape. Those other bodies that occupied the public spaces through which the 'performer' passed were the 'audience', reacting to the spectacle of exaggerated garments and wearing bodies. The garment and the wearing bodies were employed, through the very subject itself, to directly research the material implications of the body. The purpose was not to create a new reality in the landscape but, rather, to draw attention to the material significance of our body in creating the spaces that we encounter in the everyday.

The inquiry of the Conversation of Space project is executed predominantly through the making and 'performing' of garments that exist as research tools. These garments became tangible, responsive tools examining spatial encounters on a human scale. This was similar to Heidegger's original position of the body encountering 'things' in the world, though the project included bodies among the material 'things'. The garments take on strange and abstracted forms, which were designed to react and mediate between the spatiality of the human body and the place in which it exists at the time. Conceptual artist and architect Gabi Schilig refers to this method of inquiry in her work as being 'intrinsically motivated by the space of the human body ... instrumentalizing textile materiality within open spatial systems' (2009: 5). The Conversation of Space project employs a similar principle regarding the body as the primary point of departure for all investigations. The garments were tools to exaggerate perceived spatial and material properties of the body, making tangible those intangible characteristics, challenging the possible boundaries of our form. Realised at a body-scale, they are temporal in their ability to be shifted, carried through space and time, corroborated in part by the body and in part by the wider landscape. These abstract, wearable forms exist as repercussive extensions of the self-worn on our bodies and responding to our movements in an exaggerated and distorted fashion, and provoking a similar reaction from the urban landscape, which is inclusive of other bodies. Similar to underlining a word within a paragraph of text, these garments were seen as machines to highlight particular modalities of one material body in a landscape that consists of many. 


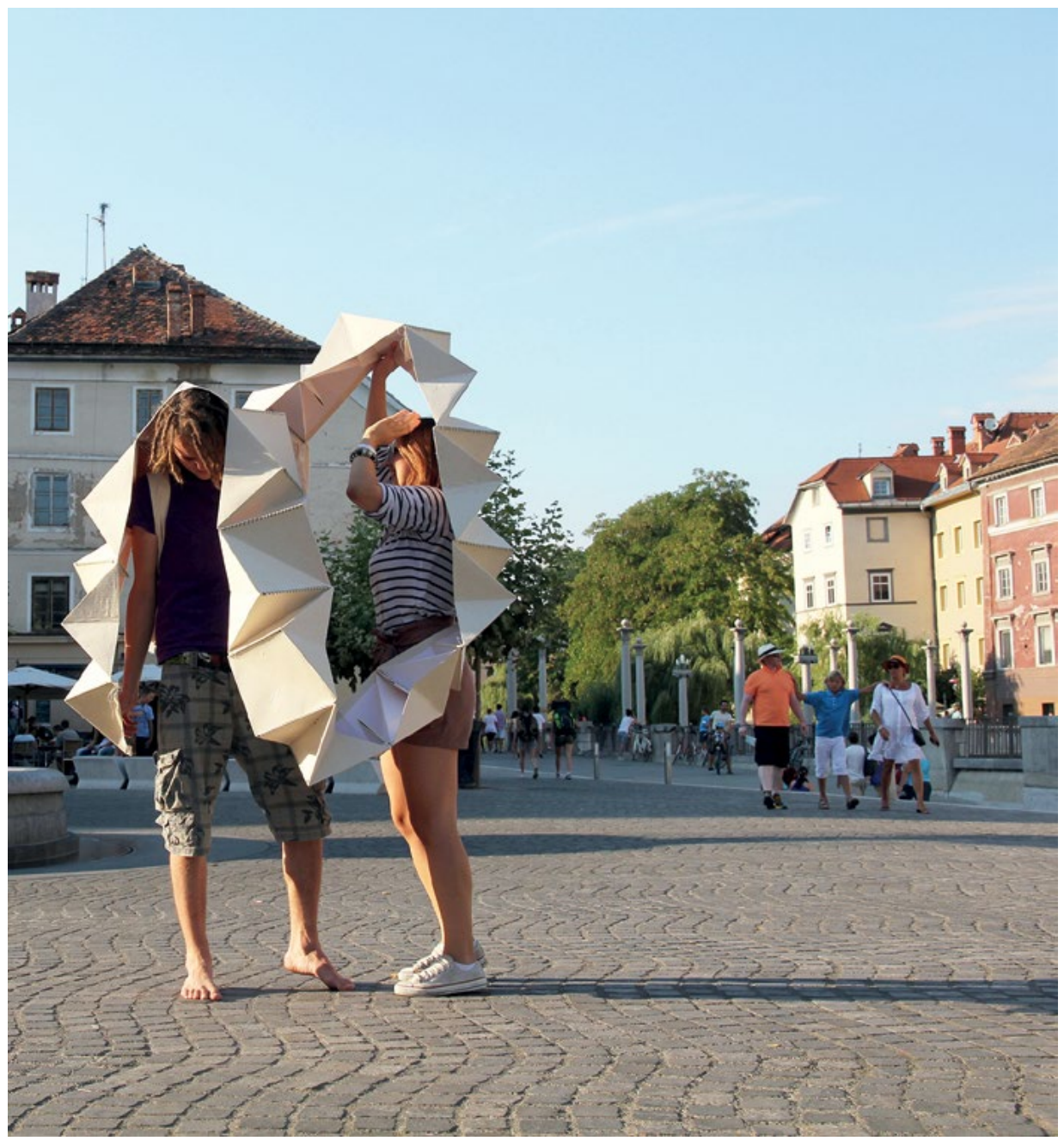

Figure 2. Social Space performance, 2011, calico, card, string, thread Photo: Alice Lewis

\section{A note on garments}

The method of employing garments as research tools, while appropriate in the context, raises the issue that adding a garment to the body will no doubt change the presented material of that body as well as the spatial scenario that occurs as a result of its presence. Returning to those choreographed bodies of the city street, however, as they move to the instructions of their traffic light conductor, the most common feature among them, aside from their bodies, was that their bodies were dressed in garments. It cannot be denied that 'human bodies are dressed bodies. The social world is a world of dressed bodies' 
(Entwistle 2007: 273). The inevitability of garments has become such that, in the spaces addressed by the Conversation of Space project (namely the public landscape of the city street), garments can be considered as equally present in the landscape as our bodies. There has indeed been a longstanding correlation between fashion and architecture, their shared motive for existence being the necessity for protection from the external world. Fashion theorist Bradley Quinn states that 'irrespective of their modern permutations and respective roles of micro and macro structures, both disciplines remain rooted in the basic task of enclosing space around the human form' (2003: 2). In a way, both forms can be seen as mediums to escape from the infiniteness of the landscape. But, it is the spaces between the architecture that interest us here. This inquiry considers garments as existing parallel to the body-parallel in that their physical form constitutes a spatial volume capable of provoking spatial change. As such, the Conversation of Space project has used garments as that aspect of the body that can be changed, enhanced and manipulated without lasting effect to the wearing body. This malleable component of the publicly visible body is the tool by which the material implications of our bodies in space is challenged.

There were three garments made for the Conversation of Space project, each one exploring a particular perceived material implication of having a body in the urban landscape. During the first few days of the workshop, I sat with the participating students on the banks of the River Ljubljanica, which weaves through central Ljubljana, Slovenia's capital city. We sat and watched the astonishingly repetitious behaviour of the mass of tourists that occupied the picturesque town that summer. We watched their habitual negotiation and unconscious engagement in the choreographed dance of the urban streetscape. Out of this mass of moving, dancing bodies we selected three separate 'material' properties of interest. What follows here is a detailed account of each investigation focusing on the garment and the performance, visualising and provoking the push and pull of the body and the landscape in which it exists, highlighting the position of the body in the urban realm and, as such, in the infinite landscape.

\section{The residual space}

As we sat and watched the people weaving through the city, we noticed a process of exchange. Footprints were left, leaves shifted by passing feet, dust was borne away on the sole of a sneaker. Perhaps even memories were distributed between bodies, left behind or taken, momentarily or forever altering the perception of the particular place for another being in the infinite landscape. And, so, the focus of this first investigation was the residual spaces that are left behind once our physical body has moved on. The idea was further developed by applying Locard's exchange principle, which is used in forensic science and which declares that the perpetrator of a crime will inevitably bring something 
to the crime scene and will leave with something from it (Horswell 2004). While this principle was originally developed to investigate crimes, the theory can also be applied to the everyday. The constant mobility of the body in the world means that this exchange of material is a ceaseless process in the landscape, a change that is primarily driven by interaction. The project deemed this to be an unchanging implication of having a body in the landscape and, as such, it is a significant material property of the body. The traces we leave become a record of where we have been and what we have done-an imprint that changes the identity of the landscape to (potential) lasting effect. Creating new places and new identities as a result of our past presence.

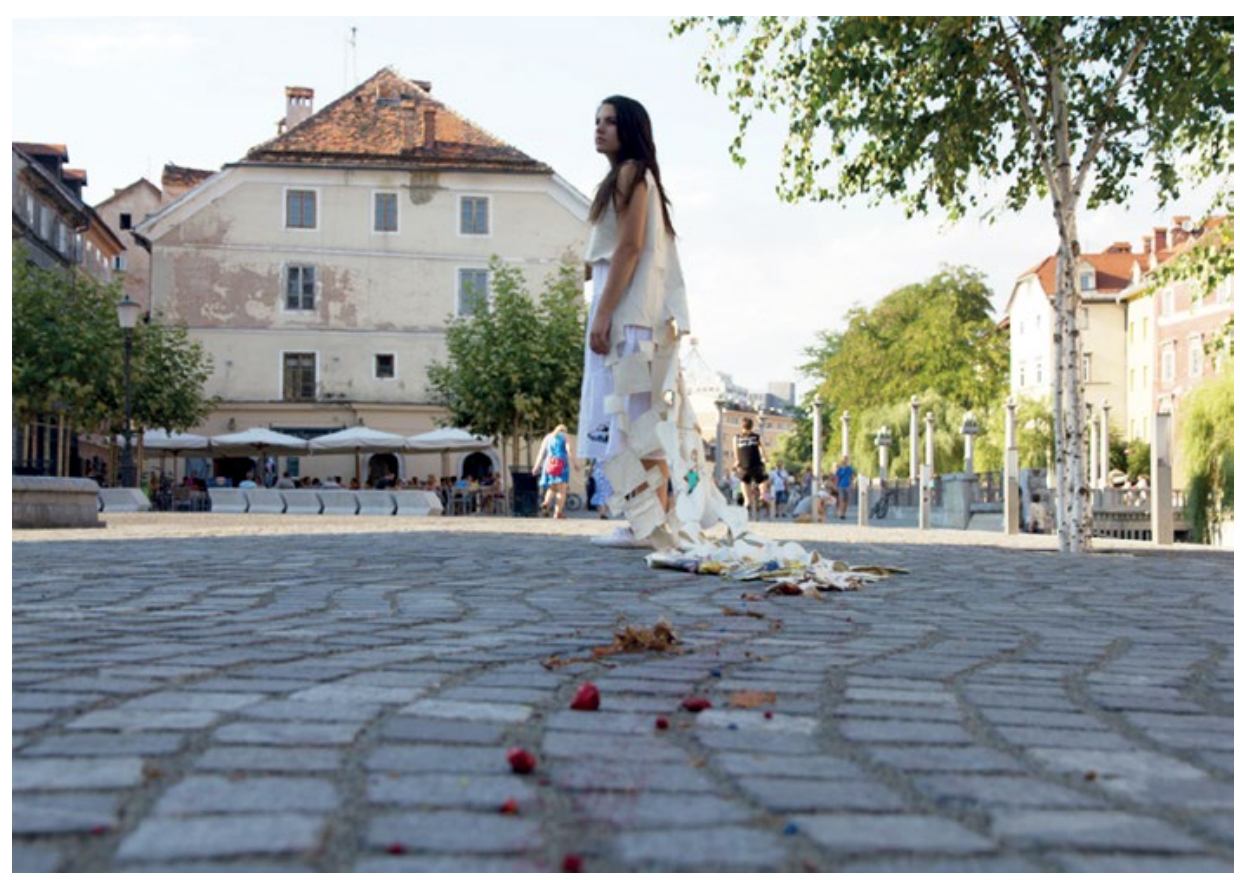

Figure 3. Residual Space performance, 2011, calico, diluted water-based pigment and rocks as weight mechanism

Photo: Alice Lewis

The garment and performance took this notion of exchange and exaggerated the process within the urban setting. The performance attempted to enhance the process from the body as well as the reciprocating landscape, bringing to the fore the dialogue between body and space. To achieve this desired reaction, a dress-like garment was made based on an accelerated process of abrasion. Unbleached ivory calico fabric and a long train that was made to drag upon the ground eerily resembled, unintentionally, a Western wedding dress, which contrasted beautifully with the gritty surfaces of the city. The train was constructed of a network of sealed calico parcels containing water-based pigment in primary colours (blue, red and yellow) with weights of various scales. As the body and 
the garment moved between the earth and sky, venturing across the public domain the weights pressed the fabric to the surface of footpath, road, bridge and so on, forcing an interaction between the textiles and the hard material of the city streets. As the body and garment traversed the surface of the world, the garment began to corrode and break away, leaving behind a wash of colour and rubble of various kinds that fell from the garment itself. The alternating colours mixed as they made contact with the ground, leaving an inventory of the wearer's journey through the space. But, as the garment dropped away, it simultaneously collected within its folds twigs, leaves, soil and other urban forage, sweeping the ground on which it lay down its colourful lines. People stopped and watched as the body and garment passed by. Some followed, others looked and continued onwards. Some even pocketed the now colourful weights. Days later, I passed the location of the performance-the absence of summer rain had left the pigment vibrant-and noticed people following the snaking line of colour. The garment had produced, in a manner of speaking, a residual path system that remained long after the garment and body had passed on.

\section{The elastic space}

This performance made physical the temporal spatial boundary occupied by our body and created by our mobile limbs. While we sat, observed and thought of how our bodies exist in the physical form, it became apparent that, while we are each a singular being, we are constructed largely of limbs hinged somewhere near the centre that are able to swing out from that central point. This structure is a necessary aspect of our being as it is what allows us to move and hence to travel through space; our legs carry us forward in a series of controlled falls, our arms balancing and protecting us, affording us the ability to grasp objects and create gestures. This customary, continual and often unconscious movement (Manning 2009) causes the boundaries of the space we occupy with our bodies to continually stretch and contract. Becoming elongated across the horizontal axis relative to our speed of travel, this boundary is temporary and ever shifting the swinging and swaying of our physical form changes the shape and size of the spaces in-between. These spaces have a malleable, elastic quality that cannot be seen except through the borders demarcated by our limbs. 


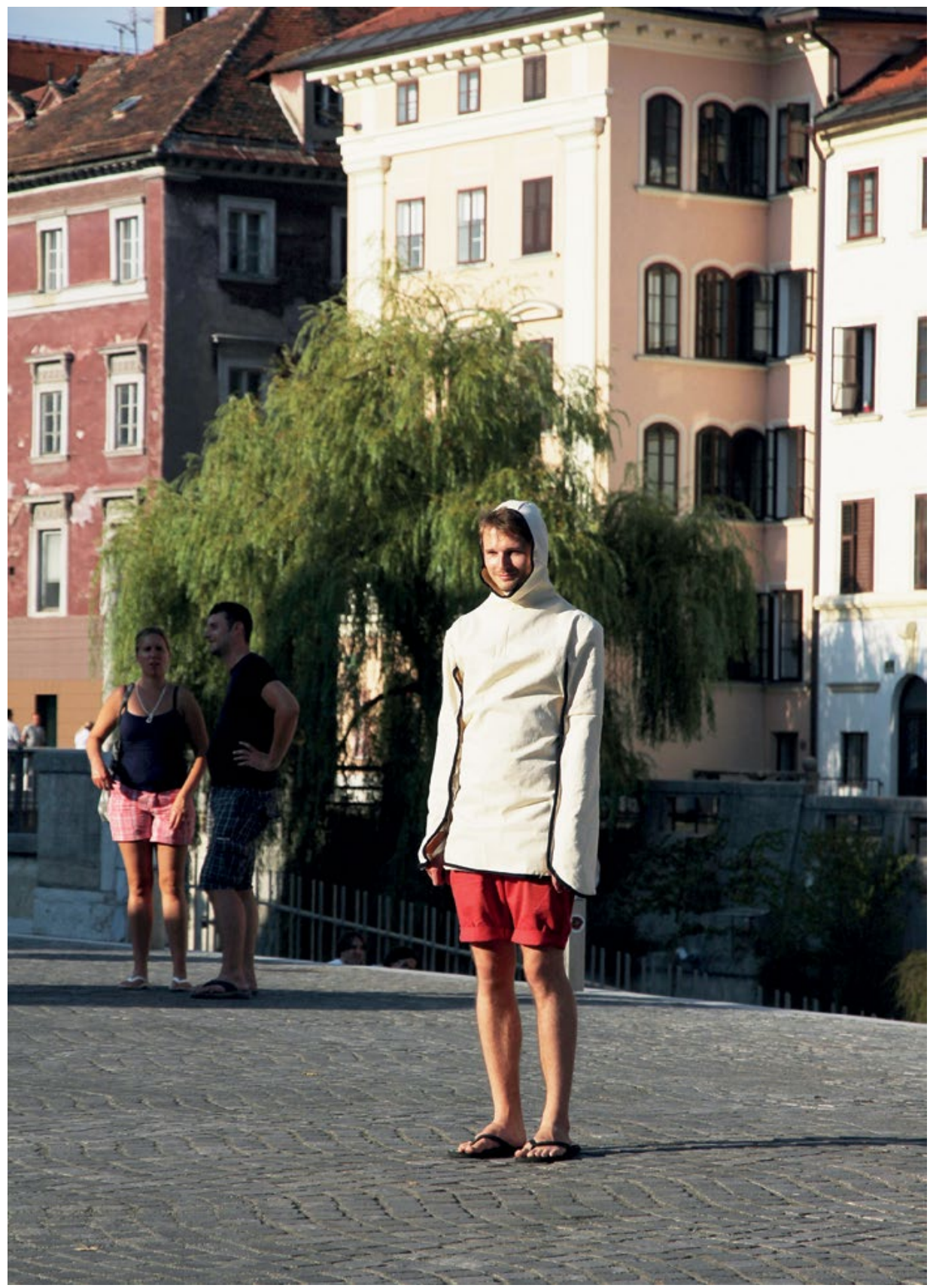

Figure 4. Elastic Space performance-Stage 1 (confines), 2011, calico, webbing, string, thread

Photo: Alice Lewis 


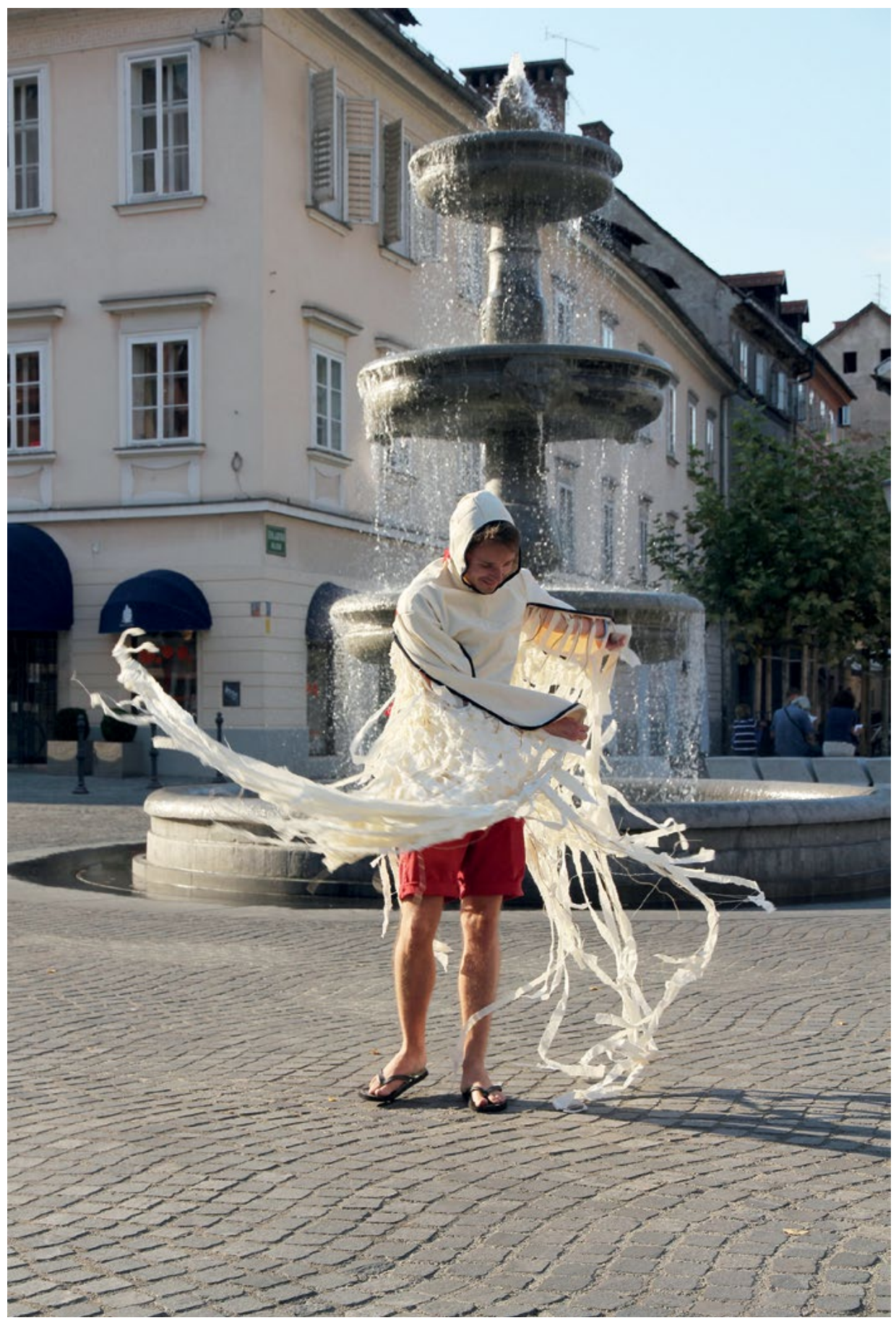

Figure 5. Elastic Space performance-Stage 2 (release), 2011, calico, webbing, string, thread

Photo: Alice Lewis 
The garment created to make visible these elastic spaces operates in a progressive fashion, first removing the elasticity of our movement and then exaggerating it through textiles; the juxtaposition of each phase causing a resounding affect on the body. In order to conduct this performance the body was first strapped into the garment, a similar process to being buckled into a straitjacket, then stitched in at the arms, which thereby inhibited all upper body movement. The legs, left free, were able to carry the wearing body through space, though the inability to engage the upper limbs in spatial interaction was an oddity. Rather than standing dormant, this process provoked the body to twist and sway. As the movement of the upper body increased, the garment responded by breaking the stitching around the arms. The inevitable movement slowly unravelled the garment itself. As the wearer became more mobile, a loosely woven fabric that was concealed in the folds of the jacket fell from the space between the arms and the side of the wearer's body. This fabric made physical those elastic in-between spaces, filling the area with wing-like sheets. While the fabric itself was not elastic in property, the loose, light structure got caught up in the air movement around the physical form, elongating their movements and making visible the invisible space. As air moved the fabric, the force that was needed to pull our arms through the space increased, each movement creating a different pull and causing the wearer to feel the space they occupied with their mobile body.

\section{The social space}

Returning again to our place on the riverbank and observing the people out on that summer day, we began to pay collective attention to the way that people were negotiating space in relation to other bodies. It occurred to me that this observation had been made previously by urbanist William $\mathrm{H}$. Whyte in his The Social Life of Small Urban Spaces (1988), in which he reveals that we (as humans) have a natural tendency to manoeuvre ourselves around the physical forms of other beings in order to successfully and succinctly carry out our traversal process. This was the very phenomenon that we were observing in Ljubljana, and it was the same thing I had observed at the traffic lights in Melbourne. People were weaving between each other, barely centimetres apart, yet it seemed they were hardly registering the other bodies, their sidesteps and speed changes almost unconscious. It was decided that the third and final garment of the Conversation of Space project would investigate this aspect of spatial occupation by creating a work that interrupted this seamless negotiation of space by inviting bodies to halt their traversal process and to physically engage with the garment and, as such, the performance.

As the garment for this final work was intended to 'invite', it was necessary that it could include a number of people within it, though multiple bodies were not necessary for the garment to move through space and hence maintain 
the temporality inherent to garments. It needed to expand and contract, cater for social inclusion but never force it. To achieve this, we developed a rigid concertina-like structure using calico, stiff card and string that could extend to meters in length but also pack down into a neat stack of tessellated triangles. The main difficulty occurred in the 'wearing' of this rigid structure on the body. After numerous failed attempts to attach the heavy object onto something wearable, the structure was transformed into an accessory and a backpack was fashioned to house it. A student wore the backpack, loaded with the garment, into the busy, bustling city square. The wearer was slowly joined by peers, each removing a little more of the elongated garment from its packed confines and encircling themselves in it. People, beginning to take notice of this expanding body-form that increasingly blocked the way, were invited to join in and to physically immerse themselves within the boundary of another social body. As people became involved, the garment stretched itself around them, creating a mass of physical material. The garment, supported by fluctuating masses of bodies produced an impermeable presence in the urban landscape. The greater the number of bodies supporting the garment, the greater their presence in the place became, exaggerating the physical space of our singular bodies, as well as the process required to manoeuvre a body around it.

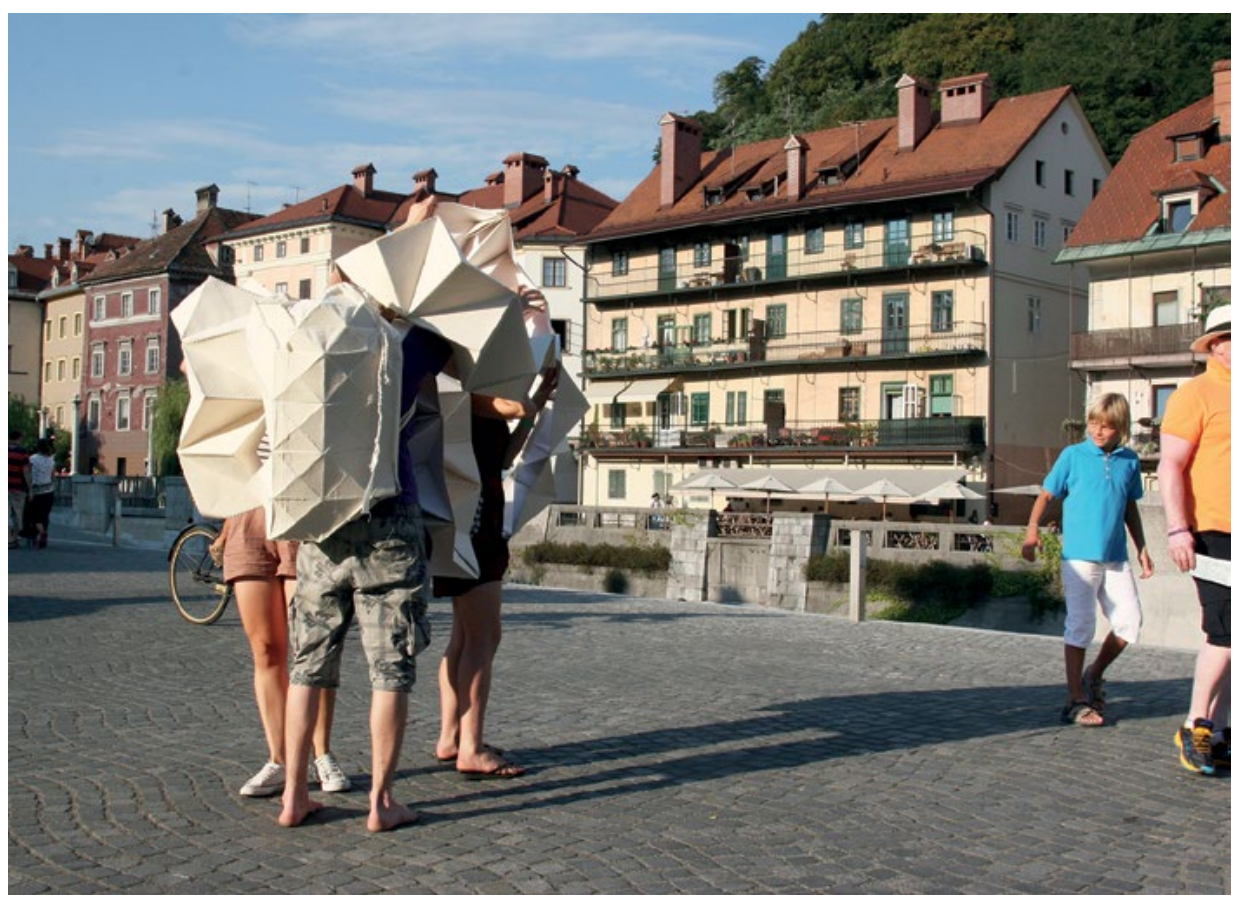

Figure 6. Social Space performance, 2011, calico, card, string, thread Photo: Alice Lewis 


\section{Findings: The implications of having a body}

There was nothing profoundly 'new' revealed through the Conversation of Space project, no 'hurrah!' moment or grand gesture though, in truth, that was not the intention. Rather the process of making and performative testing solidified that which was already speculated to be true: that our bodies (and the garments in which they are clad) are a material component of the landscape. Material insofar as we have a physical form constructed of tangible stuff that has a lasting and potentially significant effect on the immediate landscape and identity associated with that space. Take, as an example, the Social Space investigation in which the presence of the body and the garment provoked a sense of inquiry in other bodies operating in the same landscape space and caused people to stop, to engage in conversation and, to varying degrees, to actively participate in the performance itself. When this human reaction is considered in relation to the position of Otto Bollnow (1963) in which the spatiality of human life is inherently governed by those material forms that create the surrounding space then, surely, the presence of a body and garment that triggers such a spatial reaction among those similar forms is a significant material component of the space itself.

A secondary recurring observation of the Conversation of Space project was the overriding tendency to make clear the distinction between the ' $I$ ' and the 'landscape'. While the project was originally founded on the idea that our bodies are a significant part of the material landscape and, as such, its perceived identity, it appears that the separation of the body from the spaces is an unshakeable human characteristic. This, to some extent, explains the absence of the human body in Tim Ingold's earlier discussion regarding the categorisation of materials and the problematic of being a body that is both a part of the material world and is also able to engage with the material world. The conversation that was provoked throughout the performance of the Conversation of Space project brought to the forefront this keystone position of our individual existences. The centrality of our bodies to our perception is not a new phenomenon. Philosopher Maurice Merleau-Ponty asserted that 'visible and mobile, my body is a thing among things ... it is caught in the fabric of the world, and its cohesion is that of a thing. But, because it moves itself and sees, it holds things in a circle around itself' (1964: 161). So, while we must indeed be a-part-of the landscape in a material sense, the tendency to view the space around us objectively is a seemingly inescapable position. That our particular bodies are the tool through which we live and experience space, however, does not remove us from the material position as generators of both space and spatial change.

By way of conclusion, it could be said that the common linguistic use of the word 'landscape' still applies to our employment of the term today as there persists an inherent objectivity in regard to our interpretation of what the landscape 'is'. It seems, however, that this objectivity stems predominantly from our position as the central perceivers of the space around us. How, if we are engaged in 
the sensory perception of a particular place, can we be included as a-part-of it at the same moment? While the Conversations of Space project did not fully resolve this question, it was clear that the constituent part-of the landscape that our bodies are categorised as is a tactile material one. Our physical presence in space will inherently change the operation of that space. Whether it is a trace of something minute left behind as we move on, or something more present-as in our bodies causing an altered spatial scenario-our embodied existence in the world has a significant and lasting impact on the landscape that we occupy. In having a body we are always and ever materially present within the infinite landscape and, as such, are continually altering the identification that other centralised bodies may have with that particular place.

Alice Lewis is a landscape architect, fashion designer and $\mathrm{PhD}$ candidate at RMIT University in Melbourne, Australia. Her research is based around the implications and spatial relations of fashion and the human body in the urban landscape.

\section{References}

Appleton, J., 1994, The Experience of Landscape, New York: John Wiley and Sons.

Bollnow, O., 1963, Human Space, London.

Corner, J., 2002, 'Representation and landscape', in S. Swaffield (ed.), Theory in Landscape Architecture: A Reader, Philadelphia: University of Pennsylvania Press.

Entwistle, J., 2007, 'Addressing the body', in M. Bernard (ed.), Fashion Theory: A Reader, Albingdon, Oxon: Routledge Student Readers.

Gibson, J.J., 1979, The Ecological Approach to Visual Perception, Boston, Massachusetts: Houghton Mifflin.

Heidegger, M., 1971, Poetry, Language, Thought, New York: Harper \& Row Publishers.

Horswell, J., 2004, The Practice of Crime Scene Investigation, New York: Taylor \& Francis.

Ingold, T., 2011, Being Alive: Essays on Movement, Knowledge and Description, Oxford: Routledge.

Manning, E., 2009, Relationscapes: Movement, Art, Philosophy, Cambridge, Massachusetts: The MIT Press. 
Merleau-Ponty, M., 1964, The Primacy of Perception: And other Essays on Phenomenological Psychology, the Philosophy of Art, History and Politics, Evanston, Illinois: Northwestern University Press.

Norberg-Schulz, C., 1976, 'The phenomenology of place', in K. Nesbitt (ed.), Theorizing a New Agenda for Architecture: An Anthology of Architectural Theory 1965-1995, New York: Princeton Architectural Press.

Quinn, B., 2003, The Fashion of Architecture, Oxford: Berg.

Schilig, G., 2009, Mediating Space: Soft Geometries, Textile Structures, Body Architecture, Stuttgart: Akademie Schloss Solitude.

Whyte, W.H., 1988, The Social Life of Small Urban Spaces, documentary, Municipal Art Society of New York. 
This text is taken from Craft + Design Enquiry, Issue 7, 2015, edited by Kay Lawrence, published 2015 by ANU Press, The Australian National University, Canberra, Australia. 